\section{Factors affecting disclosure of serostatus to children attending Jinja Hospital Paediatric HIV clinic, Uganda}

Sophie Namasopo-Oleja $\mathrm{M}^{1}$, Danstan Bagenda², Elizabeth Ekirapa-Kiracho²

1. Jinja hospital, Paediatrics

2. Makerere University, School of Public Health, Kampala Uganda

\section{Abstract:}

Background: Disclosure of HIV status is important for optimal adherence to antiretroviral therapy in children. Identifying factors that affect disclosure of sero-status to children will help improve the process of disclosure. The purpose of the study

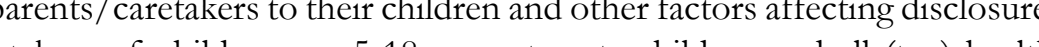
and all (ten) health workers at Jinja Hospital paediatric HIV clinic. Data was collected with standardized questionnaires on socio-demographic factors, disclosure status, health facility factors, fears and perceived benefits of disclosure.

Results: We found disclosure rates in $56 \%$ of the children. Among those not disclosed to, non-disclosure was $19 \%$ and deception $25 \%$. Factors associated with disclosure of sero-status to a child were age of child (X2 $37.4 \mathrm{df} 1 \mathrm{p}<0.001$ ), child being on antiretroviral therapy (OR 2.0 CI 1.1-3.6 $\mathrm{p}=0.024)$ and child attending psychosocial support group (OR 7.4 CI 3.6-15.3 $\mathrm{p}<0.001$ ). There were no appropriate guidelines on disclosure and only half of health providers had training on disclosure of HIV serostatus to children.

Conclusion: The overall prevalence of disclosure was low. Psychosocial support groups promoted disclosure.

Keywords: Serostatus, Paediatric HIV Clinic, Uganda

DOI: http://dx.doi.org/10.4314/ahs.v15i2.6

Introduction

ers of perinatally HIV infected children face the chalThe Joint United Nations Programme on HIV and lenge of disclosure of HIV serostatus to their infected AIDS (UNAIDS) ${ }^{1}$ estimates that 260000 children be- children. ${ }^{5}$ Benefits of disclosure include good adhercame newly infected with HIV worldwide by end of ence, ${ }^{6}$ improved healthcare and better dialogue among 2012.UNICEF ${ }^{2}$ estimates that about 190,000 children the adolescents, caregivers, and healthcare providers. aged 0-14 years in Uganda are infected with HIV. Ac- The challenges of disclosure include concerns that the cording to Ministry of Health (MOH), of the 130,000 child might be psychologically harmed or may not keep new infections that occur, about $18 \%$ is through moth- the secret $^{8}$ and fear that the stigma of AIDS will have er to child transmission of HIV (MTCT). ${ }^{3}$ The avail- a negative impact on their children and families Weinability of HIV counseling, testing, and treatment with er et al. ${ }^{9}$ Although sub Saharan Africa has one of the Antiretroviral Treatment (ART) during pregnancy has highest numbers of children with HIV, disclosure of led to a dramatic drop in the rate of perinatal trans- HIV status to infected children has received relatively mission, as well as significantly improved morbidity and little attention. ${ }^{10}$ With a high burden of HIV in children, disclosure is an issue that families, practitioners, and researchers need to address. ${ }^{5}$ As an increasing number of children born infected with HIV live to older ages, the question of when and how to talk with them about their HIV status becomes more crucial. Despite the benefits of disclosure, many parents/caretakers do not disclose to the children. ${ }^{11,12,13}$ There are few studies describing the development and evaluation of interventions to facilitate disclosure. ${ }^{5}$

In the MOH guidelines for HIV counseling and testing, it is stated that disclosure should be done at the judgment of the counselor and parent/guardian..$^{14}$ The guidelines recommend that counselors should aim at disclosing the status of children by 10 years ${ }^{14}$ and yet there are no guidelines on how this should be achieved. World Health Organization recommends that children of school age should be told their HIV positive status but the specific age appropriate counselling advise for health workers and child's parents/caregivers are not provided..$^{15}$ In Jinja Hospital, efforts have been made to encourage caretakers to disclose to children by ongoing counseling and establishing psychosocial support groups. This study explored factors affecting disclosure, its consequences and prevalence of disclosure. Identifying factors that affect disclosure of sero status in children will help improve disclosure by assisting caregivers and children deal with this difficult process.

Prevalence and patterns of disclosure

Disclosure of HIV serostatus is when the child is given information about their illness (HIV and/or AIDS). There are various patterns of disclosure, ranging from non-disclosure, partial disclosure to full disclosure. Although complete nondisclosure (no mention of HIV or of any illness) does take place, in the child's early years, partial disclosure is more common. Partial disclosure $^{16}$ is the term used for describing situations in which children are given some but not all information about their illness. When full disclosure occurs, children are told the name of the illness (HIV and/or AIDS), disease specific information, and how they acquired the disease. The rates of disclosure ranged from a low of 17 to $70 \%$ as reported in several studies, ${ }^{4,8,17,18,19,20,21,22,23,24}$ non-disclosure $23 \%$ and deception $20 \%$ particularly in young children. ${ }^{17}$ Partial disclosure was reported to vary between $35-40 \%$ by Gortmarker et al, ${ }^{4}$ and Weiner et al. ${ }^{9}$ Partial disclosure often occurs in conjunction with illness deception. ${ }^{4}$

There is controversy about the age of disclosure with some people advocating for disclosure as early as 5-7 years. ${ }^{8,23}$ Age has been reported to be the most important predictor of whether or not the child is disclosed to. 8,9

\section{Methodology}

Study setting: The study was conducted at Jinja Regional Referral Hospital Paediatric HIV clinic.

Study design: This was a cross sectional study.

Sampling and procedure: Recruitment was by consecutive enrolment. Sample size was calculated using the formula developed by Kish and Leslie ${ }^{26}, 1965$ and using $67 \%$ as the proportion of children who had been disclosed to. ${ }^{6}$ Written informed consent was obtained from caretakers. The interview was conducted by the principal investigator using a questionnaire. Inclusion criteria was primary caretakers (parent or guardian who provides majority of child's ongoing daily care) of children with HIV aged 5 to 18 years. Exclusion criteria was if the caretaker was not able to give all the required information especially with regards to disclosure. The dependent variable was disclosure of HIV sero status to the child. The independent variables were child related factors including socio demographic factors like age, sex and level of education of the child, primary caretaker factors like socio-demographic factors and relationship with the child. Health facility service factors including type of pre and post test counseling, psychosocial support groups, ongoing counseling and health service provider factors. Other independent variables included perceived benefits, reasons for disclosure, fears and problems encountered, right person to disclose and health facility factors.

Children and health workers were interviewed to supplement what caretakers reported. Assent from children above 10 years old whose caretakers had consented and to whom HIV serostatus was disclosed and caretaker thought the child could discuss issues of HIV. They were interviewed using a simplified semi-structured questionnaire to assess the level of understanding of the disease and disclosure. To avoid inadvertent disclosure, caregivers were required to confirm the child's disclosure status before the interview. Health care workers in the paediatric HIV clinic were interviewed using an interviewer administered questionnaire to explore thei opinions, experiences and attitudes regarding paediatric HIV disclosure, training on disclosure to children, existence and need for guidelines. The data was entered using EPIINFO and analysed using the SPSS version 12.0.1. To assess prevalence of disclosure, results obtained for prevalence were expressed as a percentage (the number of patients disclosed to was the numerator and total number enrolled was the denominator). Data was summarized using frequency tables for categorical data. Means and standard deviation were used to summarize continuous variables. Confidence interval of $95 \%$ was obtained and Chi-squared test was used to ascertain statistical significance of association between categorical variables and disclosure. Odd's ratio was used to determine the relative risk. P-values of below 
.05 were considered significant. Predictors of disclosure were determined using binary logistic regression analysis. Variables significantly associated with disclosure in the bivariate analysis were entered into the subsequent multivariate logistic regression models with disclosure as the dependent variable. Thematic analytic approach was used to analyse the responses to the answers by the health service providers.

Ethical clearance: Approval was obtained from Makerere University School of Public Health Higher Degrees Research and tional Council for Science and Technology. Permission was obtained from Jinja Hospital

Limitations: The study involved obtaining self reported information from respondents so there might have been bias in reporting by the caretaker especially with regards to disclosure status. We overcame this by asking probe questions to increase rigour.

\section{Results}

Profiles of the study sample

Between March and June 2009, interviews were conducted for 174 primary caretakers of children attending Jinja Hospital Paediatric HIV clinic and 20 children who had been disclosed to and whose primary caretaker had consented and thought the child was able to discuss issues related to HIV. Ten health workers were also in

\section{Table 1: Prevalence and patterns of disclosure}

\begin{tabular}{llll}
\hline Type of Disclosure & Number (\%) & $\begin{array}{l}\text { Patterns of disclosure } \\
\text { within disclosure category }\end{array}$ & Number (\%) \\
\hline Disclosed to & $98(56.3 \%)$ & Complete disclosure & $75(43.1 \%)$ \\
\hline & & Partial disclosure & $23(13.2 \%)$ \\
\hline Not disclosed to & $76(43.7 \%)$ & Complete non-disclosure & $33(19 \%)$ \\
\hline & Deception & $43(24.7 \%)$ \\
\hline
\end{tabular}

Bivariate analysis of factors associated with disclosure eight percent of the children were attending the psycho Bivariate analysis of the child related factors was done social support group and they were seven times more and the results are presented in table 2. There is a sta- likely to be disclosed to (Table 2).

tistically significant relationship between disclosure of About 58\% of the children were on ART. A child on HIV serostatus to children and age of the child ( Chi ART was twice as likely to be disclosed to $(\mathrm{p}=0.024)$. Square 37.4 with $2 \mathrm{df}$. $\mathrm{p}<0.000$ (Table 2). Disclosure is When the duration on ART was considered, those who not distributed similarly across the different age groups had been on ART for more than 12 months were more (the older children are likely to be disclosed to). Sixty likely to be disclosed to and this was statistically significant. (Table 2)

\begin{tabular}{|c|c|c|c|c|c|}
\hline \multirow[t]{2}{*}{ Variable } & \multicolumn{2}{|c|}{ Disclosure status } & \multirow[t]{2}{*}{ OR } & \multirow[t]{2}{*}{ CI } & \multirow[t]{2}{*}{ p-value } \\
\hline & $\begin{array}{l}\text { Yes } \\
\text { Number (\%) }\end{array}$ & $\begin{array}{l}\text { No } \\
\text { Number (\%) } \\
\end{array}$ & & & \\
\hline \multicolumn{6}{|l|}{ Sex } \\
\hline Male & $45(41.8)$ & $38(50 \quad)$ & 0.9 & $0.5-1.6$ & 0.6 \\
\hline Female & $53(58.2)$ & $38(50)$ & & & \\
\hline Age & & & $X^{2} 37.4$ & $\mathrm{df}=2$ & $0.000^{*}$ \\
\hline $5-7 \psi$ & $14(14.3)$ & $32(42.1)$ & 14.8 & $5.6-39.0$ & $0.000^{*}$ \\
\hline $8-10$ & $32(32.7)$ & $36(47.4)$ & 7.3 & $3.0-17$ & $0.000 *$ \\
\hline$>10$ & $52(53.1)$ & $8(5)$ & 1 & & \\
\hline \multicolumn{6}{|l|}{ On ART } \\
\hline Yes & $63(64.9)$ & $36(48.6)$ & 1.9 & $1.0-3.6$ & $0.03 *$ \\
\hline No & $34(35.1)$ & $38(51.4)$ & & & \\
\hline Duration on ART & & & $X^{2} 8.6$ & df 3 & 0.000 \\
\hline 0 months Ж & $31(33)$ & $37(52.9)$ & 2.3 & $1.0-5.1$ & 0.04 \\
\hline $0-12$ months & $19(20.2)$ & $14(20.0)$ & 1.4 & $0.6-3.7$ & 0.04 \\
\hline 13-24 months & $17(18.7)$ & $5(5)$ & 0.5 & $0.2-1.7$ & 0.5 \\
\hline$>24$ months & $27(28.7)$ & $14(20.1)$ & 1 & & $0.04 *$ \\
\hline \multicolumn{6}{|l|}{ Ariel Club } \\
\hline Yes 1 & 84 (85.7) & 34 (44.7) & 7.4 & $3.6-15.3$ & $<0.001^{*}$ \\
\hline No 2 & $14(14.3)$ & $42(55.3)$ & & & \\
\hline
\end{tabular}

* Represents the sign

$\mathrm{X}^{2} \mathrm{We}$ used the Chi Square to analyse for statistical significancy

$>10$ years $\Psi$ Is the reference category for age

$>$ months $W$ is the reference category for ART

Average age at disclosure to children was 9.22 years (s.d 3.0)

Average duration from testing to disclosure was 1.1 years with a range of zero to five years.

Bivariate analysis was done for caretaker factors and in- pared to those who had not tested. This was significantformation was collected about caretaker characteristics ly associated with disclosure to the child as illustrated in and this is presented in table 3.Those who had tested table 4 above. Relationship to the child, level of edufor HIV were 2.6 times more likely to disclose com- cation of the caretaker were not significantly associated with disclosure status of the child (Table 3).

\begin{tabular}{|c|c|c|c|c|c|}
\hline \multirow{2}{*}{ Variable } & \multicolumn{2}{|l|}{ Disclosure } & \multirow[b]{2}{*}{ OR } & \multirow[b]{2}{*}{ CI } & \multirow[b]{2}{*}{ P value } \\
\hline & Yes N (\%) & No N (\%) & & & \\
\hline \multicolumn{6}{|l|}{$\begin{array}{l}\text { Relationship to child } \\
\text { Biological parents }\end{array}$} \\
\hline & $66(67.3)$ & $51(67.1)$ & 1.1 & $0.5-1.9$ & 0.97 \\
\hline & $31(32.7)$ & $26(32.6)$ & & & \\
\hline \multicolumn{6}{|l|}{ Highest Level of education } \\
\hline 0 (None + Primary) & $84(86.7)$ & $65(43.6)$ & 1.2 & $0.5-2.8$ & 0.684 \\
\hline $\begin{array}{l}1 \text { (Post primary) } \\
\text { Occupation }\end{array}$ & $13(13.3)$ & $12(15.8)$ & & & \\
\hline $\begin{array}{l}\text { Occupation } \\
\text { Salaried + Business }\end{array}$ & $36(37.5)$ & $24(32.9)$ & 1.2 & $0.7-2.3$ & 0.54 \\
\hline Other & $60(62.5)$ & $49(67.1)$ & & & \\
\hline \multicolumn{6}{|l|}{ Caretaker ever tested } \\
\hline & $80(81.6)$ & $48(63.2)$ & 2.6 & $1.2-5.2$ & 0.006* \\
\hline $\begin{array}{l}\text { No } \\
\text { Sex of caretaker }\end{array}$ & $18(18.4)$ & $28(36.8)$ & & & \\
\hline $\begin{array}{l}\text { Sex of caretaker } \\
1 \text { Male }\end{array}$ & $19(19.4)$ & $22(28.9)$ & 0.6 & $0.3-1.2$ & 0.14 \\
\hline 2 Female & $77(80.6)$ & $55(71.1)$ & & & \\
\hline
\end{tabular}


Multiple logistic regression of factors associated with disclosure

Multiple logistic regression was used to control for confounding. All risk factors that were found to be significantly associated with disclosure of HIV serostatus to children at bivariate analysis ( $\mathrm{p}$ value $<0.05$ ), and all plausible factors that were not significant during bivariate analysis were put into logistic regression analysis (Table 4). Age of the child, being a member of the psy-

chosocial support group and caretaker having tested for HIV remained sionificantly associated with disclosure significant on multivariate analysis. Each unit increas in the age of the child increases the Odds of being disclosed to by a factor of 1.5. Attendance at a psychosocial support groups shows a positive relationship indcating that the more a person attends the psychosocia support group the higher the likelihood that the child is disclosed to.

\begin{tabular}{|c|c|c|c|c|c|c|}
\hline Variable & $\begin{array}{l}\text { Unadjusted } \\
\text { Odds Ratio } \\
\end{array}$ & $\begin{array}{l}\text { Unadjusted } \\
\text { p value }\end{array}$ & $\begin{array}{l}\text { Unadjusted } \\
\mathbf{9 5 \%} \text { CI } \\
\end{array}$ & $\begin{array}{l}\text { Odds } \\
\text { Ratio } \\
\end{array}$ & $\begin{array}{l}95 \% \\
\text { CI }\end{array}$ & p-value \\
\hline $\begin{array}{ll}\text { Member } & \text { of } \\
\text { psychosocial } & \\
\text { support group } & \end{array}$ & 7.4 & 0.001 & $3.6-15.3$ & 5.0 & $2.1-10.8$ & $<0.001^{*}$ \\
\hline Age of the child & $X^{2} 37.4$ & 0.000 & $\mathrm{df}=1$ & 1.5 & $1.2-1.6$ & $<0.001^{*}$ \\
\hline $\begin{array}{l}\text { Caretaker having } \\
\text { tested for HIV }\end{array}$ & 2.8 & 0.005 & $1.4-5.6$ & 0.5 & $0.2-0.9$ & $0.03 *$ \\
\hline Whether patient is & 1.9 & 0.03 & $1.0-3.6$ & 0.9 & $0.33-2.5$ & 0.79 \\
\hline
\end{tabular}

Eighty seven percent of the primary caretakers $87 \%$ of disclosure in children and this was included in the $(85 / 98)$ said that disclosing serostatus had helped the counseling course for paediatric HIV.

child to take drugs better, and about 10\% (9/98) felt The health workers said they were not aware of guiderelieved for telling the truth. Like the caretakers, 85 lines for disclosure in children except for one who had $\%(17 / 20)$ of the children thought it was good to be seen those adopted locally for an institution. All health disclosed to. All health workers (10/10) interviewed workers thought there was need for these guidelines at thought that the possible benefits of disclosure were National level. All health workers thought that caretakto improve adherence, positive living, improve quality ers should be supported during the process of discloof life and build self esteem and confidence among the sure especially in cases where the parents have failed to HIV positive children. Problems encountered by care- disclose. If they completely fail, then the health worker takers during the process of disclosure included not should do the disclosure.

knowing what to say $36(40 \%)$, no problem $30(34 \%)$, guilt of transmission $6(7 \%)$ and other problems 17 $(19 \%)$ included fear of many questions from the children, fear to hurt the child, not in position to handle the depression resulting from disclosure and thoughts of dying after disclosure.

\section{Health service factor}

Ten health workers in the HIV clinic were interviewed and these included; three paediatricians, one medical officer, one clinical officer, four nurse counselors and one dispenser. They handle issues of disclosure but without reference to any specific guidelines. Only five of the health workers had training directly addressing issues disclosure of HIV sero status to children aged 5 to 18 years attending Jinja Hospital Paediatric HIV clinic. We found disclosure rates in $56 \%$ of the children. Among those not disclosed to, non-disclosure was 19\% and deception 25\%. Factors associated with disclosure of sero-status to a child were age, being on antiretroviral therapy, attending psychosocial support group, and parents/caretakers having tested for HIV.

The rates of complete disclosure among HIV infected children aged 5 to 18 years in this study was $43.1 \%$ which is similar to that reported by Mialky et $\mathrm{al}^{27}$ in Philadelphia where the rate of disclosure was $43 \%$. This is possibly because the age groups studied were similar. However, the rate of disclosure in this study is higher than 19.8\% reported in Thailand by Boon-Yashidi et al. ${ }^{8}$ This could be because the age group he studied was younger. Secondly, the rates of disclosure could be higher in this study because many of the children are attending the psychosocial support groups where HIV is discussed.

In this study, partial disclosure was about $12 \%$ and this is lower than that reported by Gortmarker et al. ${ }^{4}$ who reported partial disclosure as the most common with rates of $40 \%$. This could be so because in our study, the children who were told lies about their diagnosis were categorized under non-disclosure. Gortmarker et al reported that a similar pattern of partial disclosure often occurred in conjunction with illness deception. ${ }^{4}$ Partial disclosure may be considered as part of the process of disclosure. Among children that were told lies about their illness, most of the lies were about co-morbid conditions, which seemed more acceptable and less stigmatizing. This is similar to a study reported by in which deception often entailed caregivers telling their children only about a co-morbid condition, and attributing all medical needs to that less-stigmatized condition. $^{17}$

Average age at disclosure was about 9.2 years. This is similar to other studies ${ }^{8,27}$ where the mean age of disclosure was 9.6 years and 9 years respectively. This is probably because at this age, cognitive development of illness begins. ${ }^{28}$ The youngest age of disclosure in this study was 5 years and this is in line with what some experts are advocating for, disclosure as early as 5 to 7 years. ${ }^{25,29,30}$ However, in this study, most of the caretakers thought that younger children did not seem to understand the implications of HIV diagnosis. Most of the children thought the optimal age for specific discussions about an HIV infected child's health should be conducted at an average age of 10 years. This is simila the thoughts of the care takers who suggested that to the thoughts of the care takes who suggested that delayed to a median of 10 years. ${ }^{10}$ It is also in agreement with the theory of child's cognitive understanding of illness, which considers the age from 9 to 10 years and older as the best time for HIV infected children to know about their sickness as at this age children can understand about causes of illness and its consequences. ${ }^{28}$ Attending the psycho social support group was significantly associated with disclosure and this could be because caretakers share their experiences and lessons earnt, including passing of information on HIV to children. This is similar to a study in Italy where family group psychotherapy had a positive impact on the environment of HIV-infected children, promoting psychological well-being and the disclosure of the HIV status to children. ${ }^{31}$ Being on ART and duration on ART was significantly associated with disclosure. It is similar to study by Menon et al., ${ }^{32}$ in Zambia who reported that children on antiretroviral therapy were most likely disclosed to. However the findings in this study are different from what was reported in Thailand where being on ART and duration on ART were not significantly associated with disclosure. ${ }^{33}$ This could be explained by the counseling that is done prior to starting ART in which the caretakers are given information and encouraged to disclose hence empowering the caretaker with knowledge to discuss with the child. Caretaker having tested him/herself was associated with disclosure. This is related to studies by Mellins et al., Weiner et al. and Ledlie. ${ }^{913,34}$ which showed that those caretakers who were HIV negative were likely to disclose. This is possibly because of the pre and post test counseling that the caretaker could have received when he/she had her owntest.

The investigators found that most of the caretakers $(90 \%)$, children (85\%) and all health workers though that disclosure had improved adherence. Paediatric HIV providers believe that disclosure is important for helping children understand the need for ART and create trusting relationships that facilitate adherence, ${ }^{6,35}$ In Mildmay Centre Uganda, complete disclosure of HIV status by caregivers to children and strong parental relationships were related to good adherence ${ }^{\cdot 6}$ In Brazil, Marques et al. 2006 found that despite its initial negative impact, disclosure resulted in improved healthcare and 
healthcare providers. ${ }^{7}$ This could also be explained by Behav. 2006 Jul; 10 (4 Suppl):S85-93.

the fact that when a child knows the reason why he/she is taking the medication, he is likely to co-operate. Only half of the health workers had been trained in dis- Cad Saude Publica. 2006 Mar;22(3):619-29. Epub 2006 closure to children and there were no guidelines to refer Mar 27.

to. This is similar to the situation in Thailand where 8. Boon-Yasidhi V, Kottapat U, Durier Y, et al. Diagnothere were no guidelines for disclosure ${ }^{36}$ The conse- sis disclosure in HIV-infected Thai children. J Med Asso quences of not having guidelines are that healthcare Thai. 2005 Nov; 88 Suppl 8:S100-5.

providers would approach disclosure issues differently 9. Wiener L, Battles H, Heilman N, et al. Factors Aswith uncertainty. In this study, health workers thought sociated with Disclosure of Diagnosis to Children with that the health workers role was to support the disclo- HIV/AIDS. Pediatric AIDS and HIV Infection. 1996; sure process. This is similar to a study conducted by $7(5): 310-324$.

Myer et al. 2006 in South Africa.

Conclusions: The overall prevalence of disclosure was status with infected children. J Trop Pediatr. 2006 Aug low. Parents and health workers should be adequately 52(4):293-5. Epub 2006 Mar 13

empowered to deal with the process of disclosure. Es- 11. Blasini I, Chantry C, Cruz C, et al. Disclosure tablishing psychosocial support groups, adequate coun- model for pediatric patients living with HIV in Puerseling for the care takers, training health workers and to Rico. Journal of Developmental and Behavioral Pediatrics. developing/disseminating culturally appropriate and 2004;25(3):181-189.

age-specific guidelines on disclosure of serostatus to 12. Vaz LM, Maman S, Behets F. et al. Patterns of Dischildren would help deal with the difficult process of closure of HIV Status to Infected Children in a Sub-Sadisclosure.

\section{Acknowledgement} haran African Setting J Dev Behav Pediatr. 2011 Feb 11. 13. Mellins CA, Brackis-Cott E, Dolezal C, et al. Patterns of HIV Status Disclosure to Perinatally HIV-InThis goes to Dr E. Tenywa who helped with data col- fected Children and Subsequent Mental Health Outlection, S. Namono for data entry, Albert Oleja and comes. Clinical Child Psychology and Psychiatry. to parents/caretakers who allowed to participate in the 2002;7(1):101-114. stud

14. Ministry of Health. National Implementation Guidelines for HIV counselling and Testing in Uganda 2012. pp 20-21

15. World Health Organisation Guidelines on HIV dis-

\section{References}

Joint United Nations Programme on HIV/AIDS - clos (UNAIDS) UNAIDS fact sheet 2013.

2. United Nations Children's Education Fund 16. Melvin D. Psychological Issues, challenges and (UNICEF) Uganda statistics 2012. http://www.unicef. achievements. Journal of HIV Therapy. 1999; 4(3):77-81. orginfobycountry accessed 19th July $2014 \quad$ 17. Funck-Brentano I. Informing a child about his 3. Ministry of Health 2010. Health Sector Strategic illness in HIV infection: words and meaning. Psychiatr Plan III 2010/11-2014/15 pp 13.

4. Gortmaker SL Hughe M, Cervin J, et al. Pediatric 18. Le CL, Johann Ling R. AIDS Patient Care STDS. AIDS Clinical Trials Group Protocol 219 Team. N Engl 1999 Jan; 13(1):41-5. Disclosure of the diagnosis of J Med. 2001 Nov 22;345(21):1522-1528. HIV/AIDS to children born of HIV-infected mothers 5. Wiener L, Mellins CA, Marhefka S, Battles HB Dis- 19. Negease D, Addis K, Megabiaw B. et al. HIV-Posclosure of an HIV diagnosis to children: history, cur- itive Status Disclosure and Associated Factors among rent research, and future directions. J Dev Behav Pediatr. Children in North Gondar, Northwest Ethiopia ISRN 2007 Apr;28(2):155-66

Children in North Gondar, Northwest Ethiopia ISRN AIDS. 2012 Dec 13; 2012:485720.

6. Bikaako-Kajura W, Luyirika E, Bunnel R et al. Dis- 20. Abebe W, Teferra S. Disclosure of diagnosis by parclosure of HIV status and adherence to daily drug reg- ents and caregivers to children infected with HIV: previmens among HIV-infected children in Uganda. AIDS alence associated factors and perceived barriers in Ad- dis Ababa, Ethiopia. AIDS Care. 2012; 24(9):1097-102. Lippincott Williams and Wilkins, 2002; 1119-23. 21. John-Stewart GC, Wariua G, Wamalwa D. et al Prev- 29. South African AIDS Trust (SAT) 2004. Guidelines alence, perceptions, and correlates of pediatric HIV dis- for counselling children who are infected with HIV or closure in an HIV treatment program in Kenya. AIDS Care. 2013 Sep; 25 (9):1067-76.

for counselling children who are infected with HIV or 2. Mahloko JM, Madiba S. Disclosing HIV diagnosis unond T. et al Development of a diagnosis disclosure to children in Odi District, South Africa: Reasons for model for perinatally HIV-infected children in Thaidisclosure and non-disclosure. Afr J Prim Health Care land. AIDS Care. 2013; 25(6):756-62.

Fam Med. 2012;4(1) 23. Bhattacharya M, Dubey AP, Sharma M. Patterns ily group psychotherapy to support the disclosure of of diagnosis disclosure and its correlates in HIV-In- HIV status to children and adolescents. AIDS Patient fected North Indian children. J Trop Pediatr. 2011 Dec; Care STDS. 2013 Jun; 27(6):363-9. doi: 10. 57(6):405-11. 24. Ferris M, Burau K, Schweitzer AM et al. The in- health and disclosure of HIV status in Zambian adofluence of disclosure of HIV diagnosis on time to dis- lescents with HIV infection: implications for peer-supease progression in a cohort of Romanian children and port programs. J Acquir Immune Defic Syndr. 2007 Nov teens. AIDS cre 2007; 19(9)1088-94.

25. African Network for the Care of children affected 33. Oberdorfer P, Puthanakit T, Sirisanthana T. et al. by AIDS (ANNECA). Handbook on Paediatric AIDS Disclosure of HIV/AIDS diagnosis to HIV-infectin Africa 2004 Chapter 3 Preventing Paediatric HIV in- ed children in Thailand. J Paediatr Child Health. 2006 fection pp. 35-52, Chapter 9 Adolescent issues 161-176, May;42(5):283-8

Chapter 12 Nutrition and HIV 215-228. 26. Kish, Leslie. Survey sampling New York. Wiley and sons, 1965; 49-50.

27. Mialky E, Vagnoni J, Rutstein R. School-age children with perinatally acquired HIV infection: medical and psychosocial issues in a Philadelphia cohort. AIDS Patient Care STDS. 2001 Nov;15(11):575-9

28. Schonfeld DJ. Child's cognitive understanding of illness. In Lewis M ed. Child and adolescent psychiatry: A comprehensive Text book, 3rd Edition, Philadelphia: ers to children who have perinatally acquired HIV disease: when the time comes. Nurs Res. 1999 MayJun;48(3):141-149.

35. Brackis-Cott E, Mellins CA, Abrams E, et al. Pediatric HIV medication adherence: the views of medical providers from two primary care programs. I Pediat HealthCare. 2003 Sep-Oct; 17(5):252-260.

36. Waugh S. Parental views on disclosure of diagnosis to their HIV-positive children. AIDS Care. 2003; 15:169-176. 